\title{
PENYULUHAN PEMANFAATAN LITERASI DIGITAL UNTUK PEMBELAJARAN ONLINE KEPADA ORANG TUA DAN MURID DI VILLA BALARAJA DESA SAGA BALARAJA TANGERANG
}

\author{
Nur Rizkiyah $^{1}$; Friza Youlinda Parwis ${ }^{2}$; Arinah Fransori ${ }^{3}$ \\ Universitas Indraprasta PGRI Jakarta \\ qyetaman@yahoo.com; frizayou297@gmail.com; arinahfransori@gmail.com
}

\begin{abstract}
Abstrak. Kemajuan teknologi informasi mengakibatkan arus informasi begitu cepat dan menjadi tantangan pada zaman modern saat ini, dengan pemanfaatan literasi digital dalam pembelajaran online. Metode pelaksanaan yang dilakukan dengan berbagai metode sebagai berikut. Pertama, metode ceramah dan tanya jawab. Tim abdimas memberikan materi tentang pemanfaatan literasi digital untuk pembelajaran online Kedua, praktek. Dalam kegiatan abdimas ini akan dilaksanakan ptraktek penggunaan literasi digital.. Ketiga, Publikasi. Kegiatan abdimas ini akan mempublikasikan berupa buku pemanfaatan literasi digital yang ada. Pengabdian kepada masyarakat ini dilaksanakan kepada orang tua dan murid desa Saga Balaraja Kabupaten Tangerang. Beberapa tujuan yang mendasar yang diharapkan oleh tim abdimas terhadap pelaksanaan kegiatan ini. Pertama, menjelaskan pemanfaatan literasi digital pada pembelajaran online. Kedua, mendiskusikan secara bersama mengenaipemanfaatan literasi digital pada pembelajaran online, Ketiga, mempraktekkan pemanfaatan literasi digital pada pembelajaran online

Kata Kunci: Pelatihan, pemanfaatan literasi digital pada pembelajaran online
\end{abstract}

Abstract. Advances in information technology have resulted in the flow of information so fast and become a challenge in today's modern times, with the use of digital literacy in online learning. The method of implementation is carried out by various methods as follows. First, the lecture and question and answer method. The abdimas team provides material on the use of digital literacy for online learning. Second, practice. In this abdimas activity, a practice of using digital literacy will be carried out. Third, Publication. This community service activity will publish a book on the use of existing digital literacy. This community service is carried out to parents and students of Saga Balaraja Village, Tangerang Regency. Some of the basic goals expected by the Community Service Team for the implementation of this activity. First, explaining the use of digital literacy in online learning. Second, discussing together about the use of digital literacy in online learning. Third, practicing the use of digital literacy in online learning

Keywords: Training, use of digital literacy in online learning

\section{PENDAHULUAN}

Di era revolusi keempat yang dikenal dengan revolusi digital, semua informasi dapat diperoleh dengan realtime dan cepat dimana saja dan kapan saja. Adanya mesin pencari membantu seseorang mencari bahan rujukan yang diinginkannya secara cepat dengan pembiayaan rendah. Hal ini karena bahan ajar dan aktvitas interaksi telah terdigitalisasi oleh kemajuan teknologi. Friedman(Afandi,Junanto,\&Afriani,2016) mengilustrasikanperubahaninisebagai" the world is flat" - yang merujuk pada sebuah keadaan dimana dunia tidak terbatas pada batas-batas negara dan zona waktu karena perkembangan teknologi. Perkembangan teknologi informasi telah menciptakan 
sebuah "ruang baru" yang bersifat artifisial dan maya, yang disebut cyberspace (Piliang, 2012).

$$
\text { Perkembangan }
$$

teknologi

informasi menjadi bagian dari munculnya era revolusi digital di Indonesia. Perkembangannya yang sangat pesat mampu memberikan pengaruh besar dan mendominasi seluruh sektor kehidupan masyarakat, termasuk di dunia pendidikan. dalam dunia pendidikan, khususnya pada pendidikan, memiliki konsekuensi berupa desain pembelajaran dengan memanfaatkan media digital sebagai pembelajaran online untuk meningkatkan pengetahuan orang tua dan orang tua dan murid. Media digital dapatmenyajikan materi pembelajaran secara kontekstual, audio maupun visual secara menarik dan interaktif. Orang tua dan orang tua dan murid Desa Saga, Balaraja Tanggerang sudahselayaknya menyesuaikan diri untuk menyelenggarakan proses pembelajaran berbasis digital. Penyesuaian diri Orang tua dan orang tua dan murid Desa Saga, Balaraja Tanggerang dalam pembelajaran online dengan penggunaan media digital pada proses pembelajaran menjadi hal yang urgen, pada saat ini setiap orang berusaha untuk menggali lebih jauh tentang pemanfaatan media digital untuk pembelajaran online yang mampu menjadi kekuatan untuk meningkatkan kemampuan literasi digital orang tua dan orang tua dan murid dalam dunia pendidikan.

Literasi digital dapat dilakukan dengan langkah communication and collaboration berupa partisipasi aktif dalam jaringan digital untuk pembelajaran online dan berusaha untuk menemukan sebuah model penguatan literasi digital yang dilakukan di perguruan tinggi berbasis pesantren. Villa Balaraja Desa Saga, Balaraja Tanggerang

Literasi digital adalah ketertarikan, sikap dan kemampuan individu dalam menggunakan teknologi digital dan alat komunikasi untuk mengakses, mengelola, mengintegrasikan, menganalisis dan mengevaluasi informasi, membangun pengetahuan baru, membuat dan berkomunikasi dengan orang lain agar dapat

berpartisipasisecaraefektifdalammasyarakat
Dalam konsepsi Potter (Widyastuti, Nuswantoro, \&Sidhi, 2016), usaha untuk meliterasi masyarakat berbasis digital bukan sekedar mengenalkan media digital tetapi juga menyinergikan kegiatan seharihari yang berujung padapeningkatan produktivitas. Menurut Sholihah literasi digital adalahupayauntuk menemukan, menggunakan maupun menyebarluaskan informasi secara efektif (Sholihah, 2016). Media digital merupakan jenis gawai dalam newmedia. Menurut Dennis McQuail ada empat jenis media baru, yaitu media komunikasi antar pribadi misalnya email,media permainan yang bersifat interaktif contohnya game, media pencari data atau informasi misalnya search engine di internet, dan media yang bersifat partisipasi, misalnya chatting di internet. Dalam penelitian iniyang dimaksud dengan literasi media digital adalah kemampuan dan keahlian seorang individu dalam memanfaatkan perangkat komputer, internet, dan alat-alat digital lainnya sebagai sarana penunjang aktivitas komunikasi secara optimal.

Banyak model keterampilan yang ber- manfaat untuk meningkatkan kemampuan seseorang dan kadang disebut sebagai multi literasi (Mardina, 2011). Menurut NCREL \& Metiri Group kemampuan literasi adalah kecakapan yang menekankan pada kemampuan literasi yang terkoneksi satu dengan lainnya di era digital, tidak saja terbatas pada kemampuan membaca, mendengar, menulis dan berbicara secara lisan (Burkhardt et al., 2003). Literasi digital yang juga dikenal dengan literasi komputer adalah keahlian dalam menggunakan perangkat komputer, internet, dan alat-alat digital lainnya. Literasi digital merupakan upaya to know, to search, to understand, to analyze, dan to use teknologi digital. Beetham, Littlejohn dan McGill menyebutkan ada tujuh elemen literasi digital (JISC, 2017),

Tujuh elemen literasi digital tersebut meliputi: (1) Information literacy adalah kemampuan mencari, mengevaluasi dan menggunakan informasi yang dibutuhkan secara efektif (Hasugian, 2008), (2) Digital scholarship adalah elemen yang mencakup partisipasi aktifpengguna media digital dalam kegiatan akademik untuk menjadikan informasi dari media digital 
tersebut sebagai referensi data, misalnya pada praktik penelitian ataupenyelesaian tugas kuliah (Stefani,2017), (3) Learning skills merupakan belajar secara efektif berbagai teknologi yang mempunya fiturfitur lengkap untuk aktivitas pembelajaran formal maupun informal, (4) ICT literacy atau disebut dengan melek teknologi informasi dan komunikasi yang fokus pada cara-cara untuk mengadopsi, menyesuaikan dan menggunakan perangkat digital dan media berbasis TIK baik aplikasi dan layananya. Media berbasis TIK yang dimaksud misalnya komputer atau LCD proyektor/ power point yang telah didesain/ dirancang sedemikian rupa agar dapat dimanfaatkan sesuai dengan pemahamannya, apalagi sudah terkoneksi dengan internet sebagai basis pembelajarannya (Budhirianto, 2016), (5) Career and identy management berkaitan dengan cara-cara mengelola identitas online. Identitas seseorang dapat diwakili oleh sejumlah avatar berbeda yang mampu melakukan hubungan dengan lebih dari satu pihak dalam waktu yang hampir bersamaan (Damayanti, Maria Nala; Yuwono,2013), (6) Communication and collaboration merupakan bentuk partisipasi secara aktif untuk pembelajaran dan penelitian melalui jaringan digital, dan Media literacy atau literasi media mencakup kemampuan kritis membaca dan kreatif komunikasi akademik dan profesional dalam berbagai media. Adanya literasi media membuat khalayak tidak mudah terperdaya oleh informasi- informasi yang secara sekilas memenuhi dan memuaskan kebutuhan psikologis dan sosialnya (Rianto,2016).,

(7) Elemen communicationandcollaboration menjadi fokus dalam penelitian ini. Communication and collaboration sebagai bagian dari elemen literasi digital memiliki pengertian bahwa adanya partisipasi aktif dalam jaringan digital untuk pembelajaran dan penelitian. Sedangkan menurut Stefani, communication and collaboration merupakan partisipasi aktif pengguna media digital untuk mengefisienkan waktu, hal ini erat kaitannya dengan media sebagai digital yang memiliki konvergensi (Stefani, 2017). Communication and collaboration memiliki komponen individual competence yang terdiri dari use skill yang merupakan kemampuan untuk mengakses dan mengoperasikan media, critical understanding berupa kemampuan untuk menganalisis dan mengevaluasi konten media secara komprehensif dan communicative abilities yaitu kemampuan komunikasi dan partisipasi melalui media (Commission \& Unit,2009).

\section{Permasalahan Mitra}

Literasin digital memiliki peranan penting dalam kehidupan, karena selain digunakan sebagai alat pembelajaran online literasi digital juga dapat digunakan sebagai alat komunikasi secara tulisan, di zaman era globalisasi dan pembangunan reformasi demokrasi ini, masyarakat dituntut secara aktif untuk dapat mengawasi dan memahami infrormasi di segala aspek kehidupan sosial secara baik dan benar, sebagai bahan pendukung kelengkapan tersebut, bahasa berfungsi sebagai media penyampaian informasi secara baik dan tepat, dengan penyampaian berita atau materi secara tertulis, dalam hal ini kita selaku warga negara yang baik hendaknya dalam prakteknya literasi digital diharapkan dapat digunakan dalam keseharian Masyarakat sebagai mengikuti pembelajaran online.

Berdasarkan hal ini maka dianggap perlu untuk mensosialisasikan pemanfaatan litersi digital untuk pembelajaran online kepada orang tua dan murid. Selain itu kegiatan ini diharapkan menjadi bekal serta mampu mendorong para orang tua dan murid dalam pemanfaatan literasi digital..

\section{METODE PENELITIAN}

Permasalahan umum yang terjadi adalah ketidaktahuan masyarakat tentang pemanfaatan literasi digital pada pembelajaran online. Sehingga tidak ada perhatian untuk mempelajari. Padahal selain untuk tujuan pembelajaran online , literasi digital agar orang tua dan murid memiliki kemampuan kritis membaca dan kreatif komunikasi akademik dan profesional dalam berbagai media komunikasi, pemanfaatan literasi digital merupakan alternatif dalam penggunaan pembelajaran online disamping menggunakan media lainnya. Untuk itu diperlukan sebuah sosialisasi dan pelatihan yang dapat meningkatkan pengetahuan generasi muda khususnya para orang tua dan murid terhadap kemampuan menggunakan pemanfaatan literasi digital 
sehingga mendorong mereka untuk turut mempelajarinya.

\section{Literasi Digital yang Ditawarkan}

Metode yang ditawarkan dalam kegiatan ini adalah melalui sosialisasi dengan menggunakan presentasi serta memberikan beberapa contoh dalam film yang menggunakan literasi digital yang dilakukan untuk menemukan model penguatan literasi digital. berdasarkan penelitian Nursyirwan (2015) tentang “ pemanfaatan model penguatan literasi digital di. Hal ini mendukung kebijakan Kementerian Komunikasi dan Informatika Republik Indonesia yang disampaikan dalam Siaran Pers No. 181/HM/KOMINFO/08/2018

Melalui sosialisasi ini akan diperkenalkan kepada para orang tua dan murid tentang pemanfaatan literasi digital dan informasi-informasi penting lainnya. Pada saat sosialisasi juga dibawa ontohcontoh pemanfaatan litersi digital.

\section{Tempat dan Waktu Pelatihan yang} Ditawarkan

Kegiatan ini akan dilaksanakan di Villa Balaraja Desa Saga Balaraja Tangerang.. Kegiatan ini dilakukan selama 3 bulan (Juli September 2019) dari mulai survey lokasi dan permintaan kesediaan mitra, persiapan proposal, persiapan alat dan bahan, pelaksanaan penyuluhan sampai pembuatan laporan.

\section{Langkah-langkah Metode yang Ditawarkan \\ Kegiatan ini dilakukan dalam} bentuk sosialisasi mengenai pemanfaatan literssi digital di Villa Balaraja Desa Saga Balaraja Tangerang dan sekitarnya. Sosialisasi dilakukan dengan presentasi singkat dan menonton film yang durasi singkat dan informasi-informasi penting lainnya. Selain itu juga dilakukan pelatihan tata cara pemanfaatan literasi digital secara sederhana. Untuk meramaikan kegiatan sosialisasi diselingi pula dengan permainan bagi peserta. Dan diakhir sosialisasi dalam rangka mengetahui respon dan efektivitas kegiatan, akan dibagikan kuestioner bagi para peserta sebagai parameter keberhasilan kegiatan.

\section{Partisipasi Mitra dalam Pelaksanaan Program \\ Mitra diharapkan dapat}

berpartisipasi aktif baik pada saat sosialisasi maupun pelaksanaan kegiatan. Dan hasil kegiatan ini dapat mereka gunakan baik bagi dirinya maupun lingkungan sekitarnya.

\section{HASIL DAN PEMBAHASAN}

\section{Realisasi Jadwal Kegiatan}

Pelaksanaan kegiatan berlangsung dari pertengahan bulan September 2019 Pertemuan awal dilakukan dengan perkenalan orang tua dan murid di Villa Balaraja Desa Saga Balaraja Tangerang.Pertemuan awal diperkenalkan Tim abdimas .Para orang tua dan murid juga dijelaskan tentang pemanfaatan literasi digital Para orang tua dan murid dipersilahkan bertanya. Sebagian ada bertanya tentang pemanfaatan literasi digital dalam pembelajaran online. Pertemuan berikutnya selama 45 x 2 membahas pemanfaatan literssi digital pada pembelajaran online. Pada pertemuan ini orang tua dan murid dilatih menggunakan literasi digital. Para orang tua dan murid antusias untuk mengikuti pelatihan tersebut. Pertemuan diakhiri dengan pemberian score pada masingmsing kelompok, Pertemuan ketiga, melatih soal dan penulisan di lembar jawaban selama 2 x 45 menit .

Pada pertemuan keempat ,sebelum diadakan evaluasi para fasilitator mengulang kembali,denganpemanfaatan literasi digital. Pemanfaatan literasi digital ini diajarkan bersama-sama. Satu kelompok terdiri dari 2 - 3 orang tua dan murid . Belajar secara simultan di dalam kelas.

\section{Pembahasan dan Hasil Kegiatan}

Pertemuan pertama sampai akhir sudah dilakukan.Jumlah pertemuan sebanyak 5 sesi. Orang tua dan murid nampak antusias dalam proses pelatihan pemanfaatan literasi digital yang menyenangkan dapat membantu orang tua dan murid dalam proses pembelajaranan

Pengetahuan orang tua dan murid sebelum mengikuti pelatihan pemanfaatan literasi digital untuk pembelajaran online yang menyenangkan sangat kurang tapi setelah mengikuti pelatihan pemanfaatan literasi digital .Hal ini menandakan bahwa pelatihan pemanfaatan literasi digital dapat meningkatkan pengetahuan orang tua dan murid mengenai pemanfaatan literasi digital pada pembelajaran online membantu peningkatan hasil belajar dan antusias orang tua dan murid belajar di kelas.

Pengetahuan rata-rata kelas kontrol orang tua dan murid sebelum mengikuti pelatihan pemanfaatan literasi digital sebesar61 ,sedangkan pengetahuan rata rata kelas eksperimen setelah 
mengikuti pelatihan pemanfaatan literasi digital sebesar. Dapat digambarkan pada bagan dibawah ini;

Tabel 1. Hasil Sebelum dan sesudah Pemanfaatan Literasi Digital Pada Pembelajaran Online

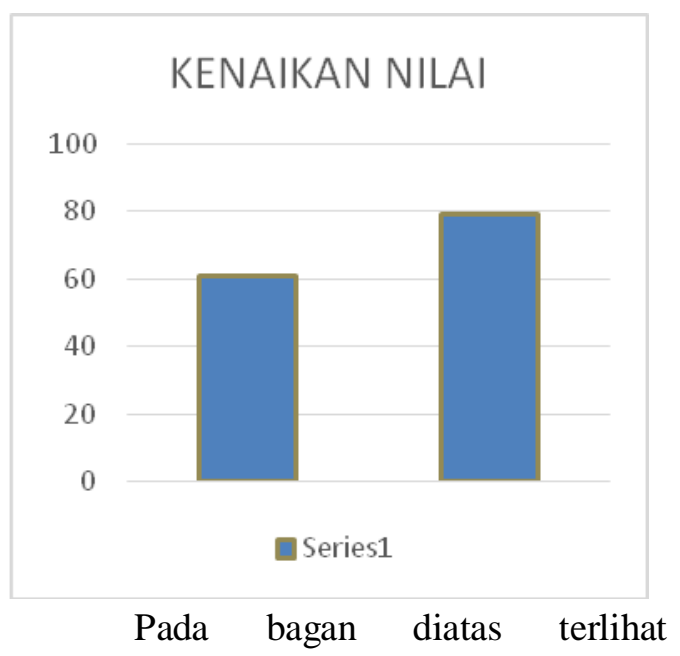

kenaikan nilai sebesar 18 point,sebelum mengikuti pelatihan pemanfaatan literasi digital 61 dan sesudah mengikuti pelatihan pemanfaatan literasi digital sebesar 79 . Hal ini menandakan bahwa pelatihan pemanfaatan literasi digital dalam pembelajaran online dapat membantu orang tua dan murid Desa Saga Balaraja Tangerang.. Diharapkan orang tua dan murid dapat menggunakan literasi digital dalam pembelajaran online.

\section{SIMPULAN.}

Kegiatan pengabdiaan masyarakat yang dilakukan ini sangat perlu dan dirasakan manfaat bagi peningkatan pengetahuan orang tua dan murid yang ada di Desa Saga Balaraja Tangerang.. Kegiatan ini juga membrikan kontibusi yang positif untuk menciptakan pembelajaran yang optimal. Kegiatan ini telah berjalan dengan baik dan dapt disimpulkan sebagai berikut :

1. Orang tua dan murid menjadi lebih termotivasi, dan memiliki ide dan gagasan terhadap pelaksanaan kegiatan pembelajaran online tersebut.

2. Orang tua dan murid perlu menciptakan pembelajaran yang kreatif dan inovatif agar orang tua dan murid siswi lebih memliliki minat dalam proses pemb.lajaran online dirumah

3. Materi pelatihan pemanfaatan literasi digital dalam pembelajaran online agar bisa diteruskan, karena pembelajaran yang menyenangkan bisa meningkatkan pengetahuan orang tua dan murid

4. Menulis mengandung manfaat bagi pengembangan mental, intelektual, sosial seseorang, serta dapat meningkatkan kecerdasan dan mengembangkan daya inisiatif dan kreatifitas.

\section{SARAN}

Dari simpulan di atas, kami mengajukan saran dan rekomendasi sebagai berikut :

1. Orang tua dan murid harus meningkatkan profesionalisme, dengan mengikuti pelatihan agar dapat memberikan ide, gagasan, serta kreatif agar proses pembelajaran online dapat terlaksana dengan baik.

2. Orang tua dan murid hendaknya tetap belajar untuk meningkatkan pengetahuan untuk kemajuan di masa depan.

3. Kesejahteraan dan kemajuan pengetahuan orang tua dan murid juga harus menjadi perhatiaan Dinas Pendidikan terkait, agar lebih termotivasi dalam belajar.

4. Kerjasama yang baik dan berkesinambungan perlu dilakukan antar lembaga sekolah, baik kepala sekolah, guru, pengawas, orang tua dan orang tua dan murid dalam meningkatkan pembelajaran yang baik, efektif dalam menghasilkan pembelajaran yang bermanfaat.

\section{DAFTAR PUSTAKA}

Hakim L. 2014.Tata Bahasa Indonesia. Malang: Selaras.

Katili AS, Zainuddin L, Mohammad CN. 2015. Penggunaan Tata Bahasa Dalam Film, Kabupaten Bonebolango, Provinsi Gorontalo. Prosiding Seminar Nasional Masyarakat Indonesia Vol. 1, Nomor 1 hal: 78-84.

Kunu PJ dan Lelolterry H. 2010. Penggunaan Tata Bahasa Dalam Karangan Di Provinsi DKI Jakarta. E-Jurnal Karangan Deskripsi Volume V(3):203-207. 